\title{
Language and space in a multilingual undergraduate physics classroom in Rwanda
}

\author{
Ingrid Andersson and Joseph Rusanganwa
}

\section{Linköping University Post Print}

N.B.: When citing this work, cite the original article.

This is an electronic version of an article published in:

Ingrid Andersson and Joseph Rusanganwa, Language and space in a multilingual undergraduate physics classroom in Rwanda, 2011, International Journal of Bilingual Education and Bilingualism, (14), 6, 751-764.

International Journal of Bilingual Education and Bilingualism is available online at informaworldTM:

http://dx.doi.org/10.1080/13670050.2011.583337

Copyright: Taylor \& Francis (Routledge)

http://www.routledge.com/

Postprint available at: Linköping University Electronic Press

http://urn.kb.se/resolve?urn=urn:nbn:se:liu:diva-72628 


\title{
Language and Space in a Multilingual Undergraduate Physics Classroom in Rwanda
}

\author{
Ingrid Andersson, * Department of Behavioural Sciences and Learning, Linköping University, \\ Sweden \\ Joseph Rusanganwa, Faculty of Arts, Media and Social Sciences, National University of Rwanda, \\ Huye-Rwanda
}

\begin{abstract}
This case study examines how a lecturer and a group of students adjust to a request for English-only medium of instruction in tertiary education. The study draws on sociocultural theories considering context and language use as tools for meaning making. Goffman's theories of stage setting and footing are used to analyse how the lecturer positions himself in relation to language use. Findings show that in the observed session the lecturer used code-switching as a tool to extend students' academic literacy. Further, in most cases he assigned different classroom spaces to different languages. Hence, English as the targeted language of instruction was used when the lecturer was standing at the board, the official teaching space, whereas French, a previously accepted language, was used in a semiofficial space closer to the students. Kinyarwanda, the lecturer's and students' first language, is not permitted as a medium of instruction, but was used when the lecturer was close to the students. We label this a personal space, where the lecturer changed code in order to improve interaction and students' understanding. Such code-switching has cultural and historical traditions and is viewed in this study as a strategy to avoid misunderstandings and allow more equitable learning opportunities.
\end{abstract}

Keywords: language policy and practice; space; footing; code-switching; tertiary education, language shift

\section{Introduction}

How do lecturers and students in tertiary education adapt to a change of medium of instruction? What language and communication strategies do they employ? These questions stimulated us to make video recordings of lessons to find out how lecturers handle this new and challenging situation. The present case study, part of a larger study on language and learning in Rwanda, investigates how a science lecturer supports a group of students to acquire and retain vocabulary selected from the lecturer's course notes in a session on English technical vocabulary on electricity. For both the lecturer and a majority of the students, English is their third or fourth language; for most, the medium of instruction in secondary education was French, but Kinyarwanda is a common language to all.

\section{Background}

To contextualize the study, we will give a brief background to changes in language policy in Rwandan higher education. The university was closed after the 1994 genocide until March 1995. When it reopened, students of all language backgrounds, returning from countries where they took refugee, were welcome to study, which meant that both Francophone and Anglophone students enrolled. To accommodate all, a policy of bilingual instruction was adopted. In practice, this meant that students were offered a one-year preparatory general language course in English or French, depending on their 
own language background. This was carried out already in 1996 when the university realized the problem and established a School of Modern Languages (Ecole Pratique des Langues Modernes, EPLM). Gradually, these language courses became compulsory. The lecturers could choose to teach in either French or English.

In October 2008, a decision was taken to change the medium of instruction in Rwandan tertiary education to English only. The change was expected to be implemented in January 2009. There were several arguments for the increased status of English, including the fact that Rwanda had been part of the East African Community since 2007 and a member of the Commonwealth since 2009 (MINEDUC 2010).

When the government took the decision to change the medium of instruction to English only, all students who wished to enter university had to accept the new language policy, namely the Requirement of English proficiency for students who join Higher Education in Rwanda (2008). The policy states that all lectures, seminars and practicals will be conducted in English, and all oral or written assessment will be in English. Further, English would be the normal language of administration of the university, for both students and staff. Students who enter higher education in Rwanda have to attend English classes to help them develop proficiency. These classes are intended to provide them with the basic language structures to enable them to develop an understanding of spoken and written language. Classes include reading of simple, general and subject-specific texts, writing of assignments, academic writing and related requirements in research skills, including paraphrasing, synthesizing, quoting, referencing and note-taking.

On entering higher education, students' ability in written and spoken English is tested and they are assigned to one of three broad categories based on their results: advanced (a score of $70 \%$ and above), intermediate (50 to 69.9\%) or beginner (less than 50\%). Appropriate English courses are provided for students judged to be 'beginners' or 'intermediate'. These courses do not carry credit, but students are reassessed at the end of Level 1 to prove their progress unless they had already been assigned to the 'advanced' category on the basis of their test results. Similarly, all lecturers have to take courses in English to be able to use English as the medium of instruction. In sum, both lecturers and students have to develop their proficiency in English and adjust to a new language culture.

In an earlier study conducted in Rwanda by Rusanganwa (2007), lecturers and students in a science faculty were interviewed on reasons for students' failure. At that time the annual intake in physics had increased from 19 students to 85, altering the teaching situation very considerably. Students' experiences of media of instruction were also diverse, as some had been taught in English and some in French. Some were taught by Rwandan lecturers and others by lecturers from abroad. In general, all interviewed lecturers tried to situate their subject in an everyday context during their introduction. Their aim was to make the students feel comfortable and confident that they would manage the course. Lecturers also referred to government directives stating that science lecturers had a particular task to increase the number of successful graduates. Students, on the other hand, expressed that fear of dropping out made them avoid subjects that were known to be demanding. 
At that time, lecturers complained about students' weak general knowledge from secondary school, their lack of motivation and their tendency to start preparing for their exams too late. Some also mentioned that using a second or third language as the medium of instruction caused problems. The students complained about their lecturers' reluctance to explain central vocabulary, their problems understanding lecturers from abroad speaking in a foreign dialect and their own tendency to have no strategy other than memorizing course notes verbatim to pass exams.

Considering the complex language situation in Rwanda and the problems shown in Rusanganwa (2007), we focus our attention here on what actually happens in a classroom after the reform for English-only instruction. Our concern is how a lecturer handles a teaching situation given the strict restrictions governing language use.

\section{Theoretical framework}

The study draws on sociocultural theories considering the importance of cultural historical contexts and the use of language as a tool for meaning making (e.g. Vygotsky 1986; 1978). It is microgenetic (Lantolf 2000) in the sense that it explores language and space over a short span where the language of instruction is changed. Hornberger (1989) claims that language use is both political and functional and that change depends on micro and macro circumstances within a society. While policymakers can take decisions based on their reasoning about political and economical globalization (Trudell 2010), educators need to consider students' understanding and ultimately deliver employable citizens. Hence, the closer one is to the actual implementation of political decisions, the more responsible one feels to allow communicative strategies that will benefit learning even if they are not in line with what is politically prescribed. Such strategies may be performed consciously, but often they are simply based on inference in response to what is interpreted as students' lack of understanding. Moreover, such deviances may take place on different footings.

\section{Footing}

Goffman (1979) investigated how people by bodily orientation, language use, tone of voice, and position in a room could shift in alignment with a group of listeners, foreground major events and bracket informal ones. He described these changes which he called footing as a change in our frame for events.

Goffman takes a clear stand against the traditional conception of face-to-face communication as something that takes place between a speaker and one or more listeners, considering only what is said. Such a position overlooks the importance of vision in how turn-taking is administered, the interpretation of facial expressions, gesticulation, back-channelling and side-involvement. Goffman analyses a communicative event as a social encounter in a participation framework. The event consists of ratified participants who can take on different roles during the event. They may be addressed or unaddressed, in the latter case they may be overhearers or bystanders. They may also engage in subordinate communication or byplay when they are unaddressed. Often students in a classroom are engaged in sideplay and thus diverge from the dominant discourse. For the purposes of the present study, Goffman's reasoning will be used in that we will analyse communication between ratified participants, a 
teacher and a group of students. However, Goffman studied interaction at utterance level, whereas we will draw on his concepts to describe how a lecturer aligns with his students in terms of space, how he positions himself in a classroom, and his use of paralinguistic expressions. Also, we use code-switching in terms of how different languages are utilized.

\section{Learning in a multilingual context}

In multilingual education, subject learning involves language learning not only as the usual need to become familiar with a certain register of a specific subject; it also includes extending an everyday vocabulary to a more academic one. Research has shown that seemingly fluent speakers of a language in face-to-face contexts experience problems when they encounter more formal education, even more so if they do not have a solid foundation in their first language (e.g. Cummins 2000; Skutnabb-Kangas 2007; Thomas \& Collier 2002). Nevertheless, lecturers, parents and policy makers in post-colonial countries continue to advocate L2/English-only policies to combat educational underachievement, despite the fact that there is no research evidence supporting such strategies (e.g. Baetens Beardsmore 2003; Cummins 2003). On the contrary, studies from Kenya (Bunyi 2005) and Tanzania (Rubagumya 1990) have shown that particularly students from rural areas who move from local language instruction to English tend to drop out and fail their exams in secondary school. Moreover, those who benefit from monolingual English instruction are the elite, an already privileged minority often educated abroad (Harlech-Jones 1998). Hence, the use of multiple languages as tools for mediating knowledge has both social and cognitive benefits, as learner confidence and participation increase (Vygotsky 1978; Lantolf 2000; Airey 2009).

In earlier studies, code-switching is discussed in terms of deficiency (Li Wei 2000). However, there is ample empirical evidence that code-switching is employed strategically by lecturers and students as a resource in many contexts - for constructing and transmitting knowledge, for classroom management and for interpersonal relations (Probyn 2009; Li Wei \& Martin 2009; Ferguson 2009). Cook (1991) asserts that different codes can be used deliberately and consciously, for example when a lecturer begins the lesson in the first language and then moves into the second and back. This is done to make the lesson as communicative as possible. The approach suggests that lecturers balance the use of languages within each lesson, allowing them to switch languages at certain key points, such as when explaining important concepts, when students are becoming distracted, during revision, or when students are praised or chided. On this basis, code-switching may be used as an effective teaching strategy for second language learning. However, it can also occur in response to verbal or non-verbal signals from students in a certain communicative framework (Goffman 1979) if conditions allow students to behave in classrooms as fluent bilinguals do (Liebscher \& Dailey-O'Cain 2005). It is this second use of languages that we will elaborate on in the present study. Hence, the following research questions are posed

- How does the teacher align with students during a teaching event?

- How are languages used during the teaching event?

- How does the use of English, French and Kinyarwanda relate to classroom space? 


\section{Method}

Data for the present study were collected in 2009 at a university involving a lecturer and students from the Departments of Physics and Applied Mathematics in the Faculty of Science during a four-week observation period including the present 90-minute video recording. All participants are Rwandans with Kinyarwanda as their common mother tongue and the lingua franca of the community. The students had recently completed their high school education (A-levels) in various schools in Rwanda. At school, French was the main medium of instruction; some schools taught a certain level of English, while others taught none at all. Like all students entering university, these students underwent language screening. All were at beginner or intermediate level in English and had taken a general English course.

The lecturer is a subject lecturer of physics but his focus in the analysed lesson is to introduce English subject-specific vocabulary. This is to prepare students for the new requirements of English as the sole medium of instruction. The setting can be described as a hybrid between a content-based classroom and an English as a foreign language (EFL) classroom.

During the data collection period, the participants used a vocabulary handout with a number of exposures to technical concepts in the field of electricity. The recording is from the fourth session of eight, that is, from the middle of the researched period. Students' exposure to vocabulary was through listening, reading, speaking and writing activities. In the recorded lesson, the lecturer did his best to help the learners to access and assimilate the target vocabulary in their long-term memory. The lecturer encouraged students to pronounce the words, read them from the handout, write down their meaning in whatever language they wished, and use them in various sentences and contexts. The analyses are inductive and inspired by field notes and our observations after watching the video several times.

Ethical considerations applicable in the context were followed. Before beginning the module where the lesson was recorded, participants were told the aims of the research and their informed consent was obtained. From the beginning of the research, participants were assured that their participation was voluntary.

\section{Findings}

The recording starts after the students and lecturer have exchanged greetings and the lecturer has informed the class about the chapter they are going to study. The lecturer had also done some preparatory work on the board in advance. In our analysis, we focus on how the lecturer positions himself in the classroom and his use of languages as these aspects intrigued our curiosity. We have split the lesson into thirds by time.

\section{The lecturer's use of the scene}

The first part of the lesson was used for introduction of the topic. The lecturer read from the course notes he shared with the students and wrote on the board. He talked while writing and making calculations, and the students followed him. From time to time the lecturer turned round to face the students, moved towards them, stopped half way, 
returned to the board and moved down close to the students. The time of change in position was registered.

After watching the video several times, we found that the lecturer throughout his teaching appeared to use space in the classroom to make his subject understood. This comprised the space between his desk and the blackboard, between his desk and close to the row of students, the space right up to the students and between the rows of individual students. In these spaces the participation framework and footing seemed to change, including language code-switching from formal and rule governed to a more informal behaviour. Between his desk and the blackboard, the lecturer seemed to use English, the language he was obliged to use. Anyone passing the classroom could see what was taking place in this space through an open door. We therefore termed it the official space.

The lecturer altered position to what we call a semi-official space, between his desk and where students were seated. We label this space semi-official as it is fairly close to the board and because the lecturer often shifted to French, the previous preferred academic language, to explain the concepts in more depth by giving examples. In this space, the students seemed to feel to a certain extent free to ask questions in French and, as the lesson progressed, also in Kinyarwanda. The lecturer answered questions by giving examples drawn from the students' background knowledge, provided they were relevant, to help them understand the concept - a sort of byplay in Goffman's terminology. It was remarkable to see how the lecturer shifted abruptly to English when he returned to the blackboard to continue his explanations.

The personal space, where the lecturer was very close to his students, was reserved for reading aloud from the course notes and interaction with students. The lecturer walked up to the students and read a definition from the handouts while they followed in their copies. This space was also used to air individual questions and give further help and clarifications. Towards the end of the lesson, it was used for language practice, where the students were requested to form sentences in English to demonstrate their understanding. They discussed any questions that arose. When the lecturer returned to the blackboard, the students used this moment to discuss among themselves, trying to figure out the meaning of the concepts explained by the lecturer. In the personal space, English, Kinyarwanda and French were mixed as a final effort to help the students understand. We label this space personal as Kinyarwanda was used. Although it has always been used to some extent, Kinyarwanda has never been permitted as a medium of instruction in higher education.

Figure 1 shows the number of changes of space related to time. As soon as the lecturer changed position we noted the time, and if he talked we noted the language he used. Analysing the activities during the lesson we discerned three phases of thirty minutes: the introductory phase (Intro), the exposition phase (Expo) and the re-capitulatory phase (Recap). 


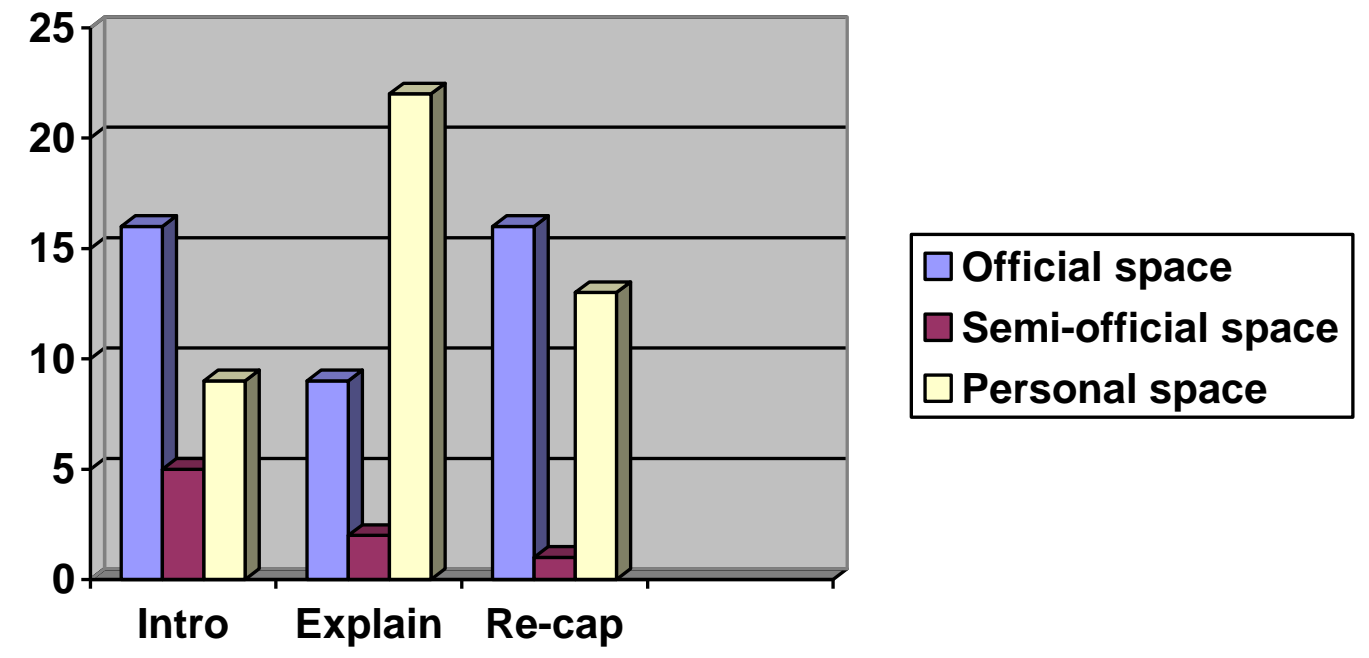

Figure 1. The teacher's use of classroom space during one lesson related to time (minutes)

Taken together, the overall picture of the lecturer's movement (Figure 1) is that the personal space is the most important, particularly during the second phase of the lesson. The semi-official space is used to a steadily decreasing extent, while the official space is used to the same degree at the beginning and end of the lesson.

During the introductory part of the lesson, we see that the lecturer used all three zones of the available space. He was often at the board writing and pointing; he moved a few steps forward to make sure the students were following, returned to the board, and moved close to the students to read and take questions. In the second phase, there was less boardwork and, hence, less time was needed in the official space. This also held for the semiofficial space. In contrast, activities in the personal space increased radically as students were uncomfortable using English. Here, the lecturer approached the students for language practice and dialogues. Towards the end of the lesson, the lecturer referred to what he had written on the board in the official space, though continued to use the personal space for recapitulation and explanations.

By maintaining eye contact with the students, the lecturer verified that the class was following him as he talked at the board. He welcomed questions and told students that they should not hesitate to ask him about anything they did not understand. The lecturer made sure that he wrote neatly and had a good outline of his presentation on the board, so that the learners could follow his presentation. He tried to speak slowly to give them time to understand. Sometimes he paused or was silent for a few minutes to give students time to process the vocabulary they had just learnt or catch up with the latest words pronounced.

\section{Code-switching}

From the above, we see that the lecturer used the classroom space for different purposes. In our analysis of the video data, we also found that the lecturer utilized all common 
languages (Figure 2) in his teaching in this hybrid lesson on technical vocabulary and physics.

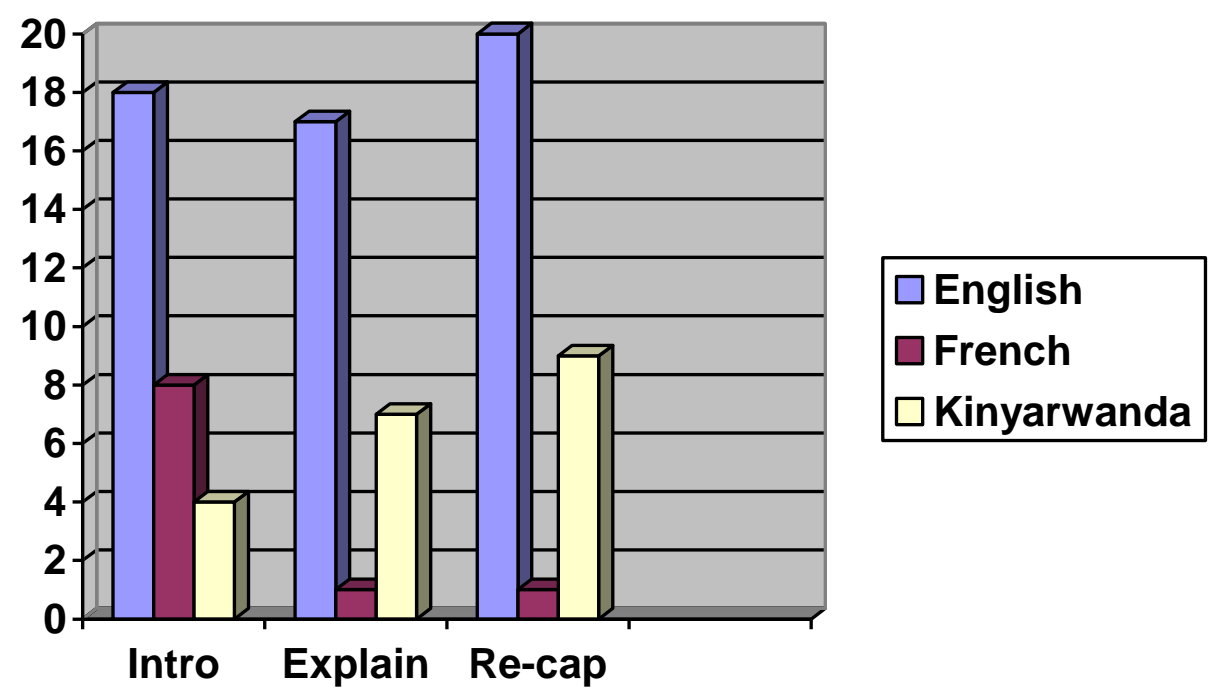

Figure 2. Language use related to lesson phases

Figure 2 shows that English was the dominant language in all three phases. The use of French gradually declines in importance, whereas Kinyarwanda increases. In this lesson, the lecturer introduced concepts from electricity including calculations on the board, writing and talking while explaining, giving definitions and providing pronunciations for the terminology in English. In the exposition phase, he focused on expanding and explicating the subject matter. Students were able to take notes on the lecturer's explanation to supplement the information in their handouts. If they wished, they could write their notes in French. Finally, he recapitulated what they had covered in the lesson. It is now interesting to examine the relationship of language to classroom space.

\section{Illustrations of language use}

Three languages were used in different spaces - official, semi-official and personal. They were used for different purposes such as introduction, exposition and recapitulation. Code-switching was used for translation, clarification, confirmation, questioning, and increased participation.

When introducing the technical vocabulary from the course notes, the lecturer used English to give definitions, explain concepts and clarify by demonstration. In the excerpt from his introduction below, the lecturer introduces the concept of an electric field:

T: An electric field at a point is defined as the force that acts on a unit positive charge placed at that point.

English was the only language used to introduce concepts throughout the session. In addition, the lecturer gave theoretical examples to illustrate the introduced concept: 
T: $\quad$ Now here we are! I suppose this charge $\mathbf{q}$ creates an electric field at point $\mathbf{p}$. Yes?

S: $\quad$ Yes

T: $\quad$ This electric field will be given like this (the lecturer writes the formula on the board)

To ensure student participation, he continuously asks them to confirm that they understand.

In order to let the concepts take hold in the students' minds, the lecturer expanded and recapitulated by giving both theoretical and practical examples. For the theoretical part, he reminded students what an electric field was by translating into French in the semiofficial space:

T: Alors, on passe. Rappelez-vous que un champs électrique est une unité d'espace où une charge subit une force électrique

(Trans: Now let's continue. Remember that an electric field is a unit of space where a charge receives an electric force)

Furthermore, the lecturer gives practical examples to show the effect of electric fields using a phenomenon from students' daily life. The students are familiar with electric cables strung up high above the ground, though they do not know why they are so high. The lecturer clarifies in Kinyarwanda in a more mundane way, telling them of the danger of going too near the cables, and here he relates to the concept of an electric field:

T: $\quad$ Ariyo mpamvu biriya bisinga by'amashanyarazi banyuza mu mujyi batabyigiza hasi.

Bacyegereje ukacyegera cyagufata.

(Trans: That's why those big electric cables they install in towns...they don't hang low to the ground. If they hang down low and you go too close, they can "grab you")

To confirm their understanding, in this session the students could use the same language as the lecturer to seek assurance. The lecturer, on the other hand, had to confirm that the students had understood what had been taught by asking them to demonstrate their understanding either verbally or non-verbally. He could for example ask whether they understood or he could recapitulate the previous concept(s):

T: Now... do you know now what we call electric field lines? Yes?

S: Yes!

$\mathrm{T}: \quad \ldots$ are the paths followed by a positive unit charge in an electric field. Yes?

Now (returns to the blackboard) now here we have electric field lines (writes on the board, murmurs the words field...lines) Is this clear?

S: $\quad$ Mhh

Most of the time students responded to their lecturer's exhortation to show their attention by prompt responses. However, sometimes the lecturer seemed to suspect that they were not following him. He then decided to recap using any of the three languages while moving to various spaces, exhorting students to recall what they had seen earlier.

As receivers of information, the students showed their participation by listening, nodding, agreeing and disagreeing, answering and asking questions. Different languages were used by students to show their participation in the session. In English and French they could assure the lecturer that they were following him by saying 'yes!' 'oui' or 
'mhh" or, occasionally, 'not' to show that they were not doing so. However, it is in Kinyarwanda, mostly mixed with French scientific terminology, that students seem to feel at ease to ask questions to verify their understanding. Here we see lots of code mixing with French and English vocabulary, and the use of some foreign words with Kinyarwanda prefixes and suffixes:

S: Nonese... kugirango izo électrons zimuvinge waplica ho champs électrique cyanga wakwaplicaho ikintu gifite charge négative cyakozwe kugirango cyaatire zimwe mu macharges ya za atomes?

(Trans: Now... in order for the electrons to move, do you apply an electric field or do you apply something that has a negative charge specially made to attract some of the atomic charges?)

Towards the end of the session, a student wants to know the effect of electric fields on different atoms. He participates by showing that he already knows something about electrons and their movement in relation to the electric field. The student also tries to ascertain whether he has clearly understood the lecture by asking questions relating to his previous knowledge.

Student participation in terms of asking questions is not frequent. However, as seen in Table 1, the lecturer shifts language frequently to increase students' understanding.

Table 1. Moments of code-switching in different classroom spaces

\begin{tabular}{lllll}
\hline Language & Official space & $\begin{array}{l}\text { Space } \\
\text { Semi-official } \\
\text { space }\end{array}$ & Personal space & Total \\
\hline English & 43 & 7 & 51 & 101 \\
French & 2 & 18 & 13 & 33 \\
Kinyarwanda & 7 & 2 & 42 & 51 \\
Total & 52 & 27 & 106 & 185 \\
\hline
\end{tabular}

Taken together, Table 1 shows that English is the dominant language in the official and personal space and French the dominant language in the semi-official space. Interestingly, code-switching is most frequent in the personal space, particularly between English and Kinyarwanda.

In line with the monolingual English rule, Kinyarwanda and French are seldom used in the official space. The lecturer used the official space for English language modelling such as pronouncing vocabulary, writing words on the board, explaining their meaning, and exhorting learners to repeat them. His tone of voice was formal, as was the language, and there was no place for gestures. He aligned with the students by looking at them. In the semi-official space where French was dominant, the lecturer talked more freely using some gestures. 
Finally, in-depth teaching of the concepts was done in close alignment to the students in the personal space. Contrary to our expectations, English dominated the personal space. In a systematic analysis we noticed that the reason for this was that the lecturer read aloud in English here. Further, actual language practice took place in the personal space as students were hesitant to speak up. The learners were required to read from their handouts and repeat the pronunciation of words. Likewise, they were required to construct sentences using the words they had learnt to imprint them in their mental lexicon. The teacher also asked them to explain the concepts to a classmate and the whole class in order to become familiar with the terms. The lecturer then went on to clarify the concepts by giving examples of their application in context. For instance, he gave an example of the 'Effet Joules (Joule's effect) to explain how electricity works in refrigerators, and students were asked to provide their own examples.

Activities during the whole lesson were dominated by the lecturer, as he initiated practically all communication. In the official space, he was writing, calculating and explaining. Occasionally he turned to the students and asked questions like 'Do you follow me?', 'Do you see?', 'Is that clear?' and the students said 'Yes' or 'Hmm'. In the semi-official space, the lecturer faced the students. He watched them closely and continued to explain in English and French using gestures and a slightly lower tone of voice. Finally, in the personal space, the lecturer lowered his voice and started talking in Kinyarwanda. In close proximity to the students, he encouraged them to feel free to ask questions in any language. During language practice he allowed long pauses for language planning and did a lot of back channelling. Once the lecturer switched to Kinyarwanda his body language became expressive, his gaze lively and he showed strong commitment to the students' learning.

The students had no dialogue with the lecturer in the official space; however, some subordinate communication took place between classmates towards the middle and end of the lesson. Sometimes the students were subvocalizing to practise the new vocabulary. The students asked a few questions in French when the lecturer used French. None of them asked questions in English. On two occasions in the personal space we could hear the students laugh. The reason they laughed was that the lecturer was able to help them understand a phenomenon, explaining it in Kinyarwanda, and even referred to a film they had seen recently. The laughter signalled surprise, relief and joy that they understood. On another occasion, one student expressed similar surprise (ah-ha!) when the lecturer codeswitched to Kinyarwanda and the student suddenly understood what the lecturer had been trying to explain at length in English.

\section{Discussion}

The present study explores space and language choice in communication while teaching students technical vocabulary in English. In this, the lecturer is attempting to conform to new language policies and at the same time strive to strengthen the students' knowledge of physics. Neither lecturer nor students are native speakers of English; however, rather than showing resistance to the language shift (Martin-Jones \& Saxena 2003), it is clear that they are aspiring to become proficient bi- or multilinguals. In this context, at least three languages are in daily use as academic tools and social resources. However, in the academic world only one language is formally accepted, meaning that students have to 
signal that they are informed about the monolingual rule and that they will adhere to it. As we see it, this is the main obstacle to student learning in the setting and it encourages both lecturer and students to employ certain strategies to cope with the situation.

The ability to switch language to cope with linguistic challenges is an important asset in the learning process. In the course of an interaction, the lecturer used one or more languages to supply the learners with appropriate words or 'chunks', elaborating on these chunks, extending the students' repertoires in various ways, prompting and guiding by asking questions, and jointly reconstructing shared experiences.

In addition to language shifts, the lecturer also exploited various positions in the classroom as spaces to deliver the knowledge required by the students. Our findings show that, particularly during the exposition phase of the lesson, he made several efforts to overcome communication problems due to the current monolingual language policy. We label these positions, which were used to engage the students in fruitful interaction, official, semi-official and personal spaces. The lecturer was able to use verbal and nonverbal communication strategies to negotiate meaning with the learners. The different spaces seemed to be used both to align with the students and avoid showing noncompliance with the monolingual rule. The strategies may be reminiscent of previous bilingual education, where switching to the mother tongue was also used to help students understand (Andersson 2008). This is in line with suggestions of current research (e.g. Li Wei 2000; Alexander 2007; Probyn 2009). However, rather than encouraging students to expand and extend word analysis in the official space using all their languages, codeswitching was used only as a last resort, preferably in the personal space to avoid being overheard by people passing the open classroom door. This is perhaps the reason why voices in the personal space were soft and low, unless the lecturer was reading aloud in English. We also see it as a way of bracketing the non-accepted language, that is, Kinyarwanda is not supposed to disturb the official communication rather enhance understanding.

Code-switching among bilingual speakers is so natural that it is not noticed. Instead, by observing their students, experienced lecturers make every effort to keep attuned to their communicative needs. The lecturer in our study seemed to attend to signals of confusion and tried to support students' understanding by all means, even if that meant using languages that are not formally accepted. He seemed to be empathetic to students' needs, a patient listener and sensitive to their language problems.

\section{Concluding discussion}

In this study, we have illuminated communication strategies employed by a lecturer to bridge the tension between the actual linguistic repertoires of students in a Rwandan university setting and the language competence to which policies in their education system aspire.

From an ecological perspective of language learning, the study shows additional affordances when code-switching was exploited for students' understanding (van Lier 2004; Martin-Jones \& Saxena 2003). Learning opportunities emerged foremost in the personal space, where misunderstandings were straightened out and co-construction of knowledge, utilizing all languages necessary, was made possible. Here students could gain a more solid foundation for their further studies. Restrictions on language use in 
classrooms hamper students' learning capacities and force them to employ learning strategies that lead to surface learning, e.g. by rote.

We agree that university students have to develop proficiency in English, but we suggest that subject lecturers in collaboration with language lecturers perform contrastive analyses of scientific vocabulary in French and English to allow students to see similarities that may not be obvious due to differences in pronunciation and lack of access to written texts. The analyses we suggest do not aim at explaining interference of linguistic systems or classifying errors (Ellis 1994) but rather to explore how French and English have influenced each other and Kinyarwanda on Physics vocabulary level and predict possible confusions in terms of false friends. This type of borrowing or transfer of vocabulary is not unique for any specific part of the world but is more or less universal. Our suggestion is in line with Doyé (2005) who claims that, to support intercomprehension between European languages of similar origin, lecturers show language learners that they can understand more of a text in a foreign language than they might expect. Moreover, we suggest that policies acknowledge the strength in lecturers' and students' linguistic competence in many registers and codes when it comes to meaning making and co-construction of knowledge. This would save time, create confidence and enable more equitable learning opportunities.

\section{References}

Airey, J. 2009. Science, language, and literacy: case studies of learning in Swedish University Physics. Acta Universitatis Upsaliensis, Uppsala Dissertations from the Faculty of Science and Technology 81. Uppsala: Uppsala University.

Alexander, N. 2007. Linguistic diversity in Africa in a global perspective. In Literacy and linguistic diversity in a global perspective,. N. Alexander and B. Busch, (Ed), pp. 1322. Graz, Austria: Council of Europe Publishing.

Andersson, I. 2008. Language codes in Rwandan secondary education: a case study (manuscript). Linköping: Linköping University.

Baetens Beardsmore, H. 2003. Who's afraid of bilingualism? In J-M Dewaele, A. Housen \& Li Wei (Eds.) Bilingualism: beyond basic principles: festschrift in honour of Hugo Baetens Beardsmor pp. 10-27. Clevedon: Multilingual Matters limited.

Bunyi, G. 2005. Language Classroom Practices in Kenya. In Lin, A. M. Y. and Martin P.W., Decolonisation, Globalisation Language-in-Education: Policies and Practice. 131-152. Clevedon: Multilingual Matters Ltd.

Cook, V. 1991. Second Language Learning and Language Teaching. Edward Arnold/ Hodder Headline Group: Melbourne.

Cummins, J. 2000. Language, power and pedagogy : bilingual children in the crossfire. Pp 56-66. Clevedon: Multilingual Matters.

Cummins, J. 2003. Bilingual education: basic principles. In J-M Dewaele, A. Housen \& Li Wei (Eds.) Bilingualism: beyond basic principles : festschrift in honour of Hugo Baetens Beardsmore, pp. 56-66.

Doyé, P. 2005. 
Ellis, R. 1994. The Study of Second Language Acquisition Oxford: Oxford University Press.

Ferguson, G. 2009. What next? Towards an agenda for classroom codeswitching research. International Journal of Bilingual Education and Bilingualism, 12:2, 231241.

Goffman, E. 1979. Footing, Semiotica 25-1/2, pp. 1-29.

Harlech-Jones, B. 1998. Viva English! Or is it time to review language policy in education? Reform Forum, February pp. 9-15.

Hornberger N. 1989 Continua of biliteracy. Review of Educational Research 59: 3, 271296.

Lantolf, J. 2000. Introducing sociocultural theory. In J. Lantolf (ed.) Sociocultural theory and second language learning. Pp. 1-26. Oxford: Oxford University Press.

Li Wei \& Martin, P. 2009. Conflicts and tensions in classroom codeswitching: an introduction. International Journal of Bilingual Education and Bilingualism, 12:2, 117-122.

Li Wei. 2000. Dimensions of bilingualism. In Li Wei (ed.) The bilingualism reader. London: Routledge. Pp.3-25.

Liebscher, G. \& Dailey-O'Cain, J. 2005. Learner code-switching in the content-based foreign language classroom. The Modern language Journal, 89, 234-247.

Martin-Jones, M. \& Saxena, M. 2003. Bilingual resources and "funds of knowledge" for teaching and learning in multi-ethnic classrooms in Britain. International Journal of Bilingual Education and Bilingualism, 6(3/4), 267-282.

MINEDUC 2010. Achievemnts 2003-2010. http://www.mineduc.gov.rw/spip.php?article27 accessed 2011-04-07.

Probyn, M. 2009. 'Smuggling the vernacular into the classroom': conflicts and tensions in classroom code-switching in township/rural schools in South Africa. International Journal of Bilingual Education and Bilingualism, 12:2, 123-136.

Requirement of English proficiency for students who join Higher Education in Rwanda. 2008. ( see http://www.nowpublic.com/world/rwanda-switch-french-english-schools Oct 14 2008; accessed 2010-07-01)

Rubagumya, C. 1990. Language in Education in Africa: A Tanzanian Perspective. London: Multilingual Matters.

Rusanganwa, J. 2007. Impact of learning strategies on the success/failure of students at NUR. (manuscript). Linköping: Linköping University.

Skutnabb-Kangas, T. 2007. Language planning and language rights. In M. Hellinger and A. Pauwels (eds.) Handbook of language and communication: diversity and change. New York: Mouton de Gruyter, pp.365- 400.

Thomas, W. \& Collier, V. 2002. A National Study of School Effectiveness for Language Minority Students' Long-Term Academic Achievement. Center for Research on 
Education, Diversity and Excellence, Santa Cruz, CA.

http://www.crede.ucsc.edu/research/1laa/1.1_final.html Accessed 20100306.

Trudell, B. 2010. 'When 'Prof' speaks, who listens? The African elite and the use of African languages for education and development in African communities. Language and Education, 24: 4, 337 - 352.

van Lier, L. 2004. The ecology and semiotics of language learning. A sociocultural perspective. New York: Kluwer Academic Publishers.

Vygotsky, L. 1978. Mind in society. The development of higher psychological processes. Cambridge MA: Harvard University Press.

Vygotsky, L. 1986. Thought and language. Cambridge Massachusetts: The MIT Press. 